\title{
KONDISI CUACA PADA SAAT JATUHNYA KINCIR ANGIN DI BARON TECHNOPARK YOGYAKARTA
}

\author{
Erwin Mulyana ${ }^{1}$
}

\begin{abstract}
Intisari
Pembangkit listrik tenaga angin merupakan salah satu sumber energi terbarukan yang sifatnya ramah lingkungan. Pada tanggal 10 Januari 2013 salah satu kincir angin pembangkit listrik di Baron Technopark jatuh sementara satu kincir angin yang lainnya baling balingnya patah. Kejadian tersebut terkait dengan adanya siklon tropis Narelle di Samudera Hindia sebelah selatan Nusa Tenggara. Pada saat kejadian, kecepatan angin di kawasan Baron Technopark mencapai 35 knot pada level ketinggian $850 \mathrm{mb}$. Intensitas hujan maksimum terjadi pada jam 01 WIB tanggal 10 Januari 2013 dengan intensitas 6 $\mathrm{mm} / 3 \mathrm{jam}$. Kemungkinan besar pada saat kincir angin jatuh terjadi kecepatan angin sesaat (gust) yang sangat kuat. Diperkirakan kecepatannya mencapai lebih dari 75 knot.
\end{abstract}

Kata Kunci : Kincir angin pembangkit listrik, Siklon Tropis Narelle, intensitas hujan, kecepatan angin, angin sesaat.

\begin{abstract}
Wind power is one of the renewable energy sources that are environmentally friendly. On January 10, 2013 one of windmill power plants in the Baron Technopark fall whiles the other windmill blades broken. The incident related to the presence of tropical cyclone Narelle in the Indian Ocean south of Nusa Tenggara. At the time of the incident, the wind speed in the Baron Technopark reached 35 knots at an altitude of $850 \mathrm{mb}$ level. The maximum rainfall intensity occurred at $01 \mathrm{pm}$ on January 10, 2013 with the intensity of 6 $\mathrm{mm} / 3$ hours. Most likely at the time of the windmill wind speed falls occur shortly (gust) is very strong. It is estimated that the speed reached more than 75 knots.
\end{abstract}

\section{PENDAHULUAN}

Pembangkit listrik tenaga angin adalah sumber energi terbarukan yang sifatnya ramah lingkungan. Secara sederhana, angin yang bertiup akan memutar baling-baling kincir angin sesuai dengan kecepatannya. Putaran kincir angin inilah yang dapat membangkitkan listrik melalui generator. Sejumlah kincir angin pembangkit listrik telah dibangun di Baron Technopark di kawasan pantai selatan wilayah Kabupaten Gunung Kidul, Yogyakarta.

Sumber energi listrik dengan memanfaatkan angin ini menjadi harapan bagi ketersediaan energi di tengah makin habisnya cadangan energi fosil atau bahan bakar minyak (BBM) yang tidak terbarukan.

Pada tanggal 10 Januari 2013 salah satu kincir angin pembangkit listrik yang berada di Baron Technopark jatuh serta satu kincir lainnya baling balingnya patah.

Pada tanggal tersebut di Samudera Hindia sebelah selatan Nusa Tenggara terdapat Tropical
Cyclone "Narelle". Cikal bakal Tropical Cyclone mulai terdeksi sejak tanggal 7 Januari 2013 berupa adanya pusat tekanan rendah di sebelah selatan Pulau Sumba.

Untuk mengetahui kondisi atmosfer pada saat kejadian tersebut, dilakukan kajian aspek meteorogi berupa analisis angin dan hujan di kawasan Baron Technopark dan sekitarnya pada tanggal 8 sampai dengan 12 Januari 2013.

\section{DATA DAN METODE}

Mengingat tidak adanya data primer berupa data pengukuran parameter cuaca di lokasi Baron Technopark, maka data yang digunakan dalam kajian ini adalah data sekunder yaitu gradient winds analysis yang diambil dari Bureau of Meteorology Australia. Analisis gradient winds ini digunakan untuk melihat pergerakan udara di wilayah Indonesia dan sekitarnya yang mempengaruhi kondisi atmosfer di kawasan Baron Technopark. 
Data lain yang digunakan adalah perkembangan dan pergerakan siklon tropis Narelle dari Joint Typhoon Warning Center (JTWC) United States Navy, data angin dari NCEP - NOAA serta data hujan Tropical Rainfall Measuring Mission (TRMM) dari NASA.

\section{HASIL DAN PEMBAHASAN}

Kawasan Baron Technopark berada pada koordinat $110^{\circ} 32^{\prime} 32^{\prime \prime}$ BT - 110 $3^{\prime} 45^{\prime \prime}$ BT dan $8^{\circ} 7$ '52" LS - 8²'7". Lokasiya berada di pantai selatan Jawa di wilayah Kabupaten Gunung Kidul, Daerah Istimewa Yogyakarta. Tofografinya berupa bukit-bukit kecil dengan ketinggian bervariasi mulai dari 0 meter sampai dengan 50 meter di atas permukaan laut. Vegetasi berupa rumput, semak dan pepohonan dengan ketinggian kurang dari 10 meter. Pengaruh angin laut sangat dominan di kawasan tersebut.

\subsection{Tropical Cyclone Narelle}

Tanggal 8 Januari 2013, Joint Typhoon Warning Center (JTWC) mengumumkan terbentuknya badai tropis "Narelle", yang terletak sekitar $135 \mathrm{~km}$ sebelah Selatan - Tenggara P. Sumba. Badai tropis ini berasal dari depresi tropis, yang terbentuk di sekitar P. Timor pada "Palung Muson" ("Monsoon Through") yang membentang dari Timur ke Barat di Lautan Hindia sampai Lautan Pacific, mulai tanggal 4 Januari 2013.

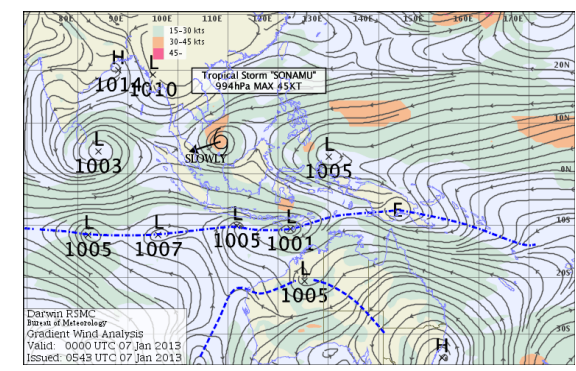

Gambar 1. Gradient winds analysis tanggal 7 Januari 2013 jam 07:00 WIB. Tanda L merupakan pusat tekanan rendah. (diambil dari BOM).

Gambar 1 menunjukkan palung muson yang membentang dari Lautan Hindia sampai dengan Lautan Pasifik. Tekanan rendah $(1001 \mathrm{mb})$ di sebelah selatan Pulau Sumba menunjukan lokasi depresi tropis. Suhu muka laut yang hangat (30 $31^{\circ}$ C) di sekitar Pulau Sumba memungkinkan depresi tropis semakin menguat dan menjadi badai tropis yang diberi nama "Narelle". Badai tropis "Narelle" meningkat menjadi siklon tropis
"Narelle" sekitar lokasi (12S, 118E) pada tanggal 8 Januari 2013.

Siklon tropis "Narelle" terus menguat dengan cepat. Tanggal 9 Januari 2013, Bureau of Meteorology meningkatkan status Siklon Tropis "Narelle" menjadi severe tropical cyclone (siklon tropis kuat) dengan perkiraan kecepatan angin tangensial mencapai $120 \mathrm{~km} / \mathrm{jam}$ (64 knot). Pada tanggal 11 Januari, siklon tropis "Narelle" mencapai puncaknya dengan kecepatan angin tangensial mencapai $185 \mathrm{~km} / \mathrm{jam}$ (100 knot) dan tekanan udara pada level muka laut mencapai 930 mb. Tanggal 12 Januari siklon tropis mulai menurun kekuatannya, dan pada 13 Januari "Narelle" sudah dibawah kategori siklon tropis kuat. Akhirnya, tanggal 15 Januari Buerau of Meteorology mengumumkan bahwa "Narelle" sudah berakhir.

Perkembangan dan lintasan siklon tropis "Narelle" dari mulai terbentuk sebagai depresi tropis, menguat dan sampai akhirnya disipasi disajikan pada Gambar 2. Tanda $L$ dalam lintasan Siklon Tropis menunjukkan sistem tekanan rendah, sementara angka $(2-4)$ menunjukkan kategori siklon tropis "Narelle". Sementara Gambar 3 menunjukkan citra siklon tropis "Narelle" saat mencapai kategori 4 pada tanggal 11 Januari 2013.

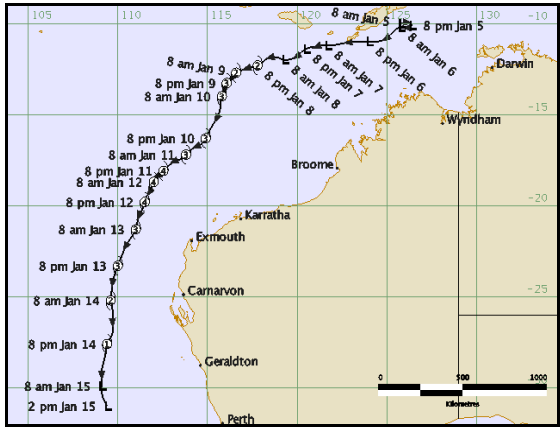

Gambar 2. Lintasan siklon tropis "Narelle" sejak mulai terbentuk sebagai depresi tropis. Angka pada lintasan adalah kategori siklon yang menunjukkan kekuatan siklon tropis. (Diambil dari Bureau of Meteorology): http://www.bom.gov.au/announce ments/sevwx/wa/watc20130105.s $h t m l)$

Menurut Bureau of Meteorology Australia, siklon tropis dibagi menjadi 5 kategori (Tropical cyclone Category System) yaitu :

Kategori 1 (siklon tropis).

Angin terkencang kategori 1 tidak terlalu merusak (Gales) dengan kecepatan gust wind (angin sesaat) di atas lahan datar mencapai $90-125 \mathrm{~km} / \mathrm{jam}$.

Kategori 2 (siklon tropis): 
Angin terkencang kategori 2 bisa merusak dengan kecepatan gust wind di atas lahan datar mencapai 125 - $164 \mathrm{~km} / \mathrm{jam}$.

Kategori 3 (siklon tropis kuat):

Angin terkencang kategori 3 sangat merusak dengan kecepatan gust wind di atas lahan datar mencapai $165-224 \mathrm{~km} / \mathrm{jam}$.

Kategori 4 (siklon tropis kuat):

Angin terkencang kategori 4 sangat merusak dengan kecepatan gust wind di atas lahan datar mencapai 225 - 279 km/jam.

Kategori 5 (siklon tropis kuat):

Angin terkencang kategori 5 sangat merusak dengan kecepatan gust wind di atas lahan datar mencapai lebih dari $280 \mathrm{~km} / \mathrm{jam}$.

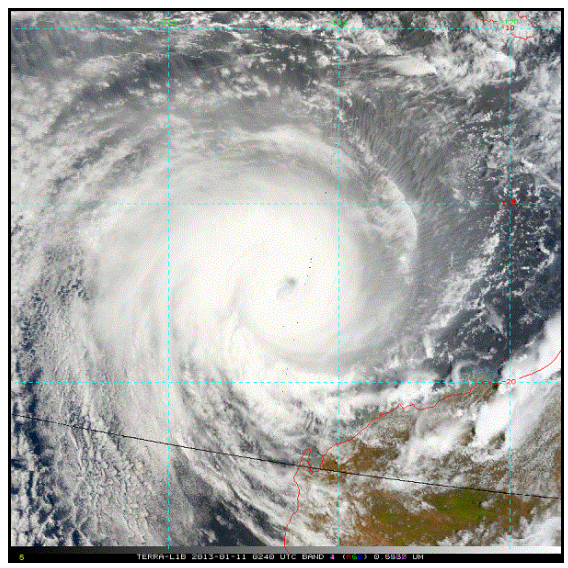

Gambar 3. Citra satelit siklon tropis "Narelle" sekitar (18S,113E) pada tanggal 11 Januari 2013, jam 09:40 WIB (diambil dari JTWC).

Gambar 4 adalah gradient wind analysis tanggal 11 Januari 2013 jam 07.00 WIB, tampak siklon tropis "Narelle" mencapai kategori 4 dan posisinya berada di sebelah selatan-tenggara pantai Baron. Wilayah Jawa Tengah - sampai Bali kecepatan anginnya berkisar antara 35 - 45 knot (65 - $83 \mathrm{~km} / \mathrm{jam}$ ). Sementara siklon tropis bergerak ke arah Barat Daya dengan kecepatan 7 knot.

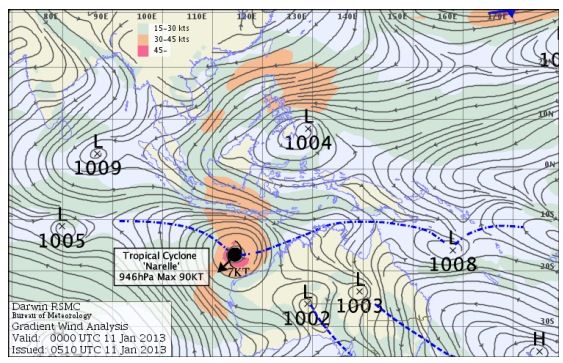

Gambar 4. Gradient winds analysis, 11 Januari 2013 jam 07:00 WIB (dari BOM)

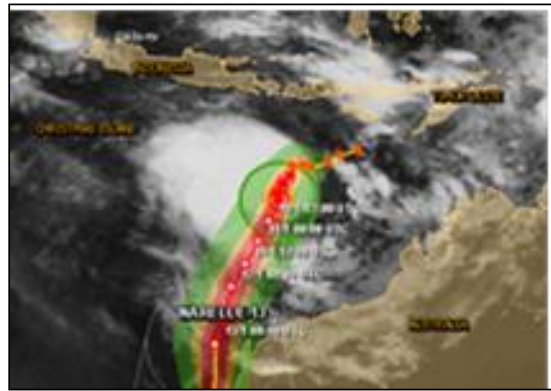

Gambar 5. Posisi "Narelle" pada tanggal 10 Januari 2013 jam 19:00 WIB. (Dari www.gdacs.org.)

Pada Gambar 5 saat "Narelle" mencapai kategori 3, tutupan awan di wilayah Jawa hampir clear. Hal ini menunjukkan bahwa dengan meningkatnya kecepatan angin di pusat "Narelle", kecepatan angin di wilayah Indonesia terutama yang berdekatan dengan "Narelle" juga meningkat akibat besarnya perbedaan tekanan udara (pressure gradient).

\subsection{Analisis Angin}

Berdasarkan data angin dari NOAA, terlihat adanya peningkatan kecepatan angin yang signifikan di kawasan Baron Technopark dan sekitarnya pada tanggal 9 - 11 Januari 2013 seperti diperlihatkan pada Gambar 6. Hal ini berkaitan dengan adanya Siklon Tropis Narelle yang berada di sebelah selatan Jawa.

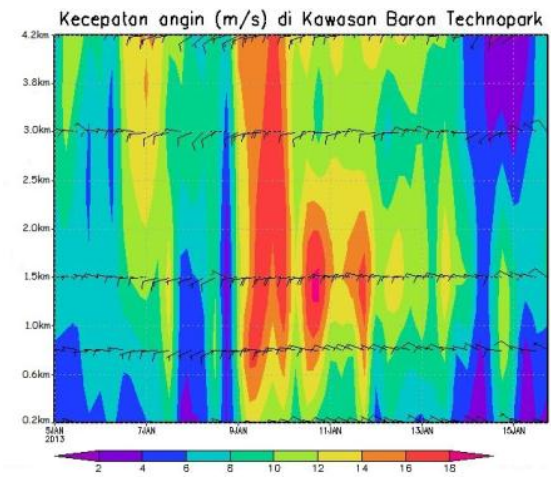

Gambar 6. Kecepatan angin di sekitar Baron (8.00S,110.50E) pada ketinggian 0.2 s.d. $4.2 \mathrm{~km}$ pada tanggal 5 s.d. 15 Januari 2013.

Gambar 6 menunjukkan kecepatan angin di Kawasan Baron Technopark Yogyakarta untuk berbagai ketinggian (0.2 s.d. $4.2 \mathrm{~km}$ ) pada tanggal 5 s.d. 15 Januari 2013. Tampak adanya perubahan kecepatan angin yang signifikan pada tanggal 9 - 11 Januari terutama antara level 0.7 
s.d. $2.5 \mathrm{~km}$. Tanggal 9 - 11 Januari merupakan saat terjadinya peningkatan status siklon tropis "Narelle" dari siklon tropis kategori 2 menjadi kategori 4.

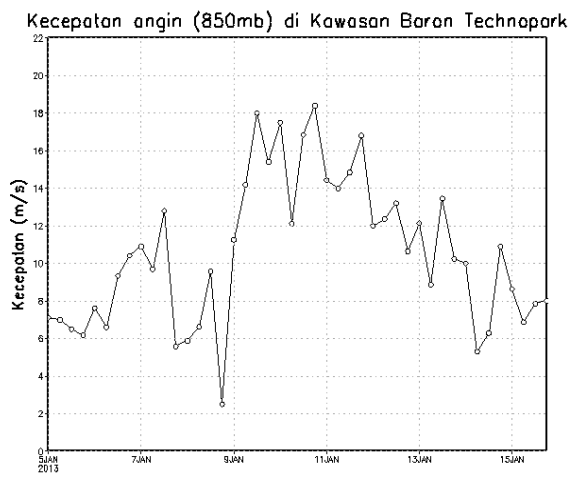

Gambar 7. Kecepatan angin di kawasan Baron Technopark tanggal 5 - 15 Januari 2013 pada level $850 \mathrm{mb}$.

Jika ditinjau lebih dalam perubahan kecepatan angin pada level $850 \mathrm{mb}(10.000 \mathrm{ft}) \mathrm{di}$ sekitar wilayah Baron, jelas tampak terjadi lonjakan kecepatan angin pada tanggal $9-11$ Januari 2013 seperti yang terlihat pada Gambar 7. Pada tanggal 9 januari 2013 siang terjadi peningkatan kecepatan angin hingga $14 \mathrm{~m} / \mathrm{s}$ (27 knot). Kecepatan angin terus meningkat hingga mencapai 18 m/s (35 knot). Kondisi angin kencang ini terus bertahan hingga tanggal 11 Januari 2013. Kecepatan angin maksimum mencapai lebih dari $18 \mathrm{~m} / \mathrm{s}$ (35 knot) pada jam 01 WIB tanggal 11 Januari 2013.

Jika dilihat distribusi spasial kecepatan angin rata rata pada level $850 \mathrm{mb}$ tanggal 10 Januari jam 12 Z - 18 Z (10 Januari jam 19 WIB s.d 11 Januari jam 03 WIB), terlihat di kawasan Baron dan sekitarnya termasuk daerah dengan kecepatan tinggi (lebih dari $16 \mathrm{~m} / \mathrm{s}$ atau $31 \mathrm{knot}$ ) seperti yang tampak pada Gambar 8 .

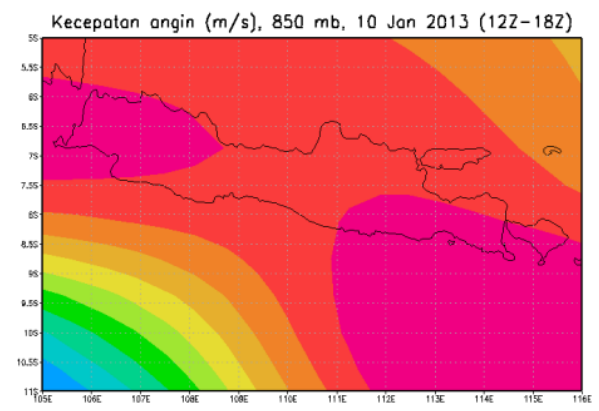

Gambar 8. Kecepatan angin rata-rata pada level $850 \mathrm{mb}$ (5000 kaki) tanggal 10 Januari 2013 jam 12 Z - 18 Z (19 WIB 10 Januari - 03 WIB 11 Januari 2013) di wilayah Jawa dan sekitarnya.

\subsection{Analisis Hujan}

Berdasarkan data hujan 3 jam-an yang diambil dari TRMM pada tanggal 8 s.d 12 Januari 2013, di kawasan Baron Technopark hampir terjadi hujan setiap hari, kecuali tanggal 12 Januari 2012. Mengacu kepada klasifikasi hujan dari BMKG, intensitas hujan yang terjadi selama periode tersebut termasuk hujan dengan intensitas ringan (1-5 mm / jam). Grafik kejadian hujan selengkapnya disajikan pada Gambar 9.

Kejadian hujan 3 jam-an pada tanggal 9 Januri 2013 jam 18 Z (10 Januari 2013 jam 01 WIB) meliputi wilayah sepanjang pantai selatan Jawa Tengah, Yogyakarta, hingga Jawa Timur. Konsentrasi hujan berada di kawasan Baron Technopark hingga ke sebelah timur dengan intensitas $6 \mathrm{~mm} / 3 \mathrm{jam}$. Hujan pada tanggal 10 Januri 2013 jam 18 Z (11 Januari 2013 jam 01 WIB) intensitasnya semakin berkurang yaitu kurang dari $2 \mathrm{~mm} / 3$ jam dengan sebaran yang semakin sempit. (lihat Gambar 10 dan Gambar 11).

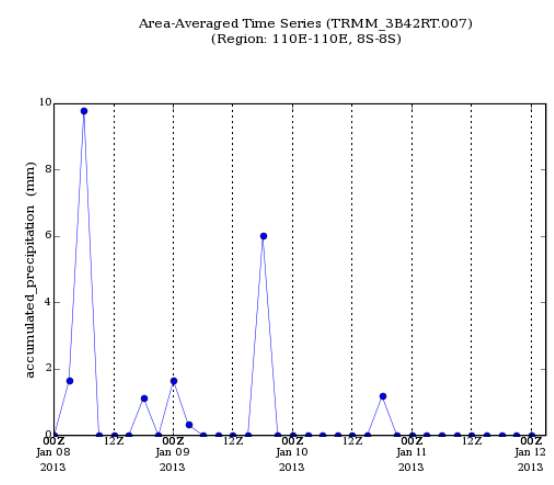

Gambar 9. Kejadian hujan pada tanggal 8 s.d 12 Januari 2013 di Kawasan Baron Technopark berdasarkan data hujan TRMM 3 jam-an.

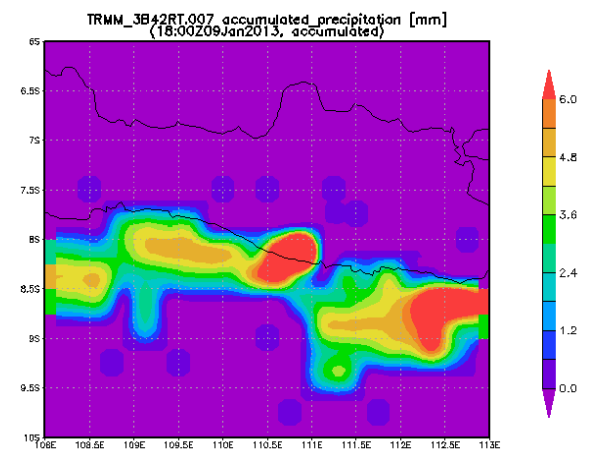

Gambar 10. Distribusi hujan pada tanggal 9 Januari 2013 jam 18 Z (10 Januari 2013 jam 01 WIB) berdasarkan data hujan TRMM 3 jam-an 


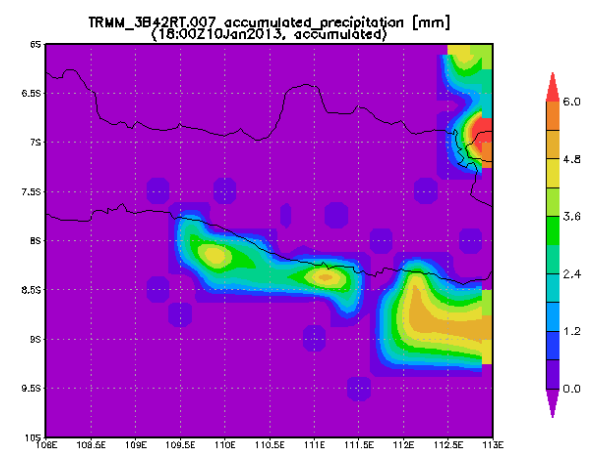

Gambar 11. Distribusi hujan pada tanggal 10 Januari 2013 jam $18 \quad$ Z (11 Januari 2013 jam 01 WIB) berdasarkan data hujan TRMM 3 jam-an

\section{KESIMPULAN DAN SARAN}

Dari analisis data angin dan hujan tersebut dapat disimpulkan bahwa:

a. Angin kencang yang dirasakan di sekitar Baron Technopark terkait dengan adanya siklon tropis "Narelle" yang meningkat kekuatannya dari kategori 2 menjadi kategori 4.

b. Kecepatan angin level $850 \mathrm{mb}$ (5000 feet) di Kawasan Baron Technopark pada tanggal 9 s.d 11 Januari 2013 mencapai $18 \mathrm{~m} / \mathrm{det}$ atau setara dengan 35 knot.

c. Intensitas hujan yang terjadi di Kawasan Baron Technopark pada tanggal 9 s.d 11 Januari 2013 adalah intensitas ringan. Intensitas hujan maksimum terjadi pada jam 01 WIB tanggal 10 Januari 2013 dengan intensitas $6 \mathrm{~mm} / 3 \mathrm{jam}$.

d. Kemungkinan besar pada saat turbin angin jatuh pada tanggal 11 Januari dini hari terjadi gust wind yang sangat kuat yang terjadi hanya dalam beberapa detik.

Dari pengalaman kejadian ini, disarankan di Baron Technopark dipasang alat ukur parameter cuaca otomatis seperti arah dan kecepatan angin, suhu udara, tekanan udara, kelembaban udara, dan curah hujan.

\section{DAFTAR PUSTAKA}

1. Global Disaster and Alert and Coordination Sistem. www.gdacs.org

2. Gradient Wind Analysis. http://www.bom.gov.au/australia/charts/g/w 00 z.shtml. Diakses tanggal 8 Januari 2013.

3. Joint Typhoon Warning Center. http://www.usno.navy.mil/JTWC/.

4. Tropical Cyclone Category System. http://www.bom.gov.au/cyclone/about/intensity.

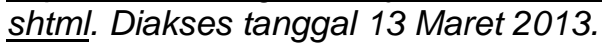

5. Tropical Rainfall Measuring Mission. http://trmm.gsfc.nasa.gov/

6. Severe Tropical Cyclone Narelle. http://www.bom.gov.au/announcements/sevwx/ wa/watc20130105.shtml. Diakses tanggal 13 Maret 2013. 